\title{
A NEW METHOD OF AIR-TEMPERATURE MEASUREMENT IN URBAN CLIMATOLOGICAL STUDIES
}

\author{
L. A. Conrads and J. C. H. van der HaGe \\ Department of Meteorology, State University of Utrecht, Utrecht, The Netherlands
}

(First received 14 January 1971 and in final form 1 April 1971)

\begin{abstract}
To suppress the recording of temperature variations caused by small scale convective air movements from hot paving or car exhausts, an air-temperature is recorded which is the average temperature from four positions on a horizontal line across the front of a car, spaced at $0.5 \mathrm{~m}$ intervals at a height of $2 \mathrm{~m}$ above the ground.

Mean air-temperatures, based on data from 90 traverses through the City of Utrecht in December 1969, January and February 1970, and the influence of a city-square on the horizontal temperature distribution are discussed.
\end{abstract}

\section{INTRODUCTION}

WHEN using data on atmospheric stability in studying air-pollution, we encounter the problem of the applicability of measurements from meteorological towers in the open field to the atmospheric environment of a city.

To answer the question, whether the influence of the heat island phenomena of a relatively small city in a flat country near the sea on the overall horizontal and vertical temperature distribution can be neglected, an urban climatological programme was started with some research into the method of air-temperature measurements in cities and a study of horizontal air-temperature variations in the City of Utrecht.

A system of thermo-couples was used as an air-temperature sensor and mounted on the roof (at the front) of a VW-bus.

One of the conditions in the design of a temperature recording system for cityclimatological purposes was to be able to observe the influence of cross-roads on the air-temperature of a street. Experimental runs showed, especially on sunny days, that vertical air motions were connected with horizontal temperature variations up to $0.5^{\circ} \mathrm{C}$ within $1 \mathrm{~m}$, at a height of $2 \mathrm{~m}$ above the ground. A single motor vehicle could produce similar variations.

In the ideal conception of a city-traverse, the streets are considered as one dimensional structures, and temperature differences across the width of a street are not considered. To reconcile this with reality, we defined the air temperature as the mean temperature of a cross section of the traffic road at a height of $2 \mathrm{~m}$. Without some agreement of this kind we find it impossible to describe air temperatures along a traverse with a precision better than $0.5^{\circ} \mathrm{C}$. This definition necessitated the positioning of more than one sensor in a row across the car.

Experimentally, it appeared that four sensors spaced at $0.5 \mathrm{~m}$ intervals were sufficient to define a temperature profile along a street, reproducible within $0 \cdot 1{ }^{\circ} \mathrm{C}$. This was tested with a second car, fitted with the same equipment, following the first at some distance between 10 and $50 \mathrm{~m}$.

Small scale temperature variations along the axis of the street, as caused, for example, by a single stationary motor vehicle, can seriously complicate the interpretation of the recordings. 
The time constant of the measuring system, if it is large enough, smoothes out such interferences together with temperature influences of cross-roads. By experiment, it was found that a time constant of 2.5 s produced an acceptable recording in which the major crossroads were still discernible when driving at normal city speed $(\leqslant 40 \mathrm{~km}$ $\left.h^{-1}\right)$. At night, sensors with a much smaller time constant can be employed.

\section{EQUIPMENT}

Four copper-constantan thermo-couples spaced at $0.5 \mathrm{~m}$ intervals at a height of $2 \mathrm{~m}$ above the ground, arranged as a thermopile to measure the average temperature from four positions, are mounted separately in double walled radiation screens, each fitted with a rain shield and a funnel-shaped device to maintain a constant ventilation of about $5 \mathrm{~m} \mathrm{~s}^{-1}$ at all driving speeds.

This ventilation is provided by an electric fan, connected to the thermo-couple houses with p.v.c. piping (see FIG. 1). The cold junctions of the system are immersed in a Dewar flask with petroleum, the temperature of which can be read from a calibrated thermometer with an accuracy up to $0 \cdot 1^{\circ} \mathrm{C}$. For a zero check this temperature is recorded by pushing a button which creates a short in the system, every 15 min when a stop is made.

A second reference point on the recording is made by another pushbutton, which switches from the air-temperature junctions to a set of similar thermo-couples in a petroleum bath on the outside of the car. The temperature of this bath is also read from a calibrated thermometer at each stop; it is always close to the ambient temperature because the bath is not provided with any heat insulation.

The system is connected to the $2 \mathrm{mV}$ input of a "Servogor" strip chart-recorder, corresponding to $0.05^{\circ} \mathrm{C} \mathrm{mm}^{-1}$ on the strip. The recorder is mounted on $15 \mathrm{~cm}$ of foam rubber, and has a stabilized electronic $220 \mathrm{~V}$ a.c. supply which is fed from a car battery.

\section{AIR-TEMPERATURE PROFILES ACROSS THE CITY OF UTRECHT}

Morning traverses are taken from a routine-programme of afternoon and morning crossings every day through the city and its neighbourhood during December 1969, January and February 1970. The City of Utrecht has 278,000 inhabitants and its built-up area is about $53 \mathrm{~km}^{2}$.

Each day the traverse started at 7.30 a.m. Mean European Time (M.E.T.) (that is about $1 \mathrm{~h}$ before sunrise) on the east side of the city. The traverse of $14 \mathrm{~km}(11 \mathrm{~km}$ as the crow flies) was covered within 30 min. Thermograph recordings of "De Bilt", a major meteorological station $3 \mathrm{~km}$ from the centre of the city, were used for the corrections of temperature changes with time when necessary. Preselected topographic points were marked with the aid of an event-marker connected with the "Servogor" recorder. FIGURE 2 shows the E-W route with some of the preselected points and indicating the position of the square Neude (Ne), an open square of approximately $7000 \mathrm{~m}^{2}$ in the centre of the city.

FIGURES $3 \mathrm{a}, \mathrm{b}$ and $\mathrm{c}$ show mean air-temperature profiles at $7.30 \mathrm{~h}$ M.E.T. for December 1969, January and February 1970.

The monthly mean temperatures were calculated from 31, 31 and 28 traverses in the morning respectively. 


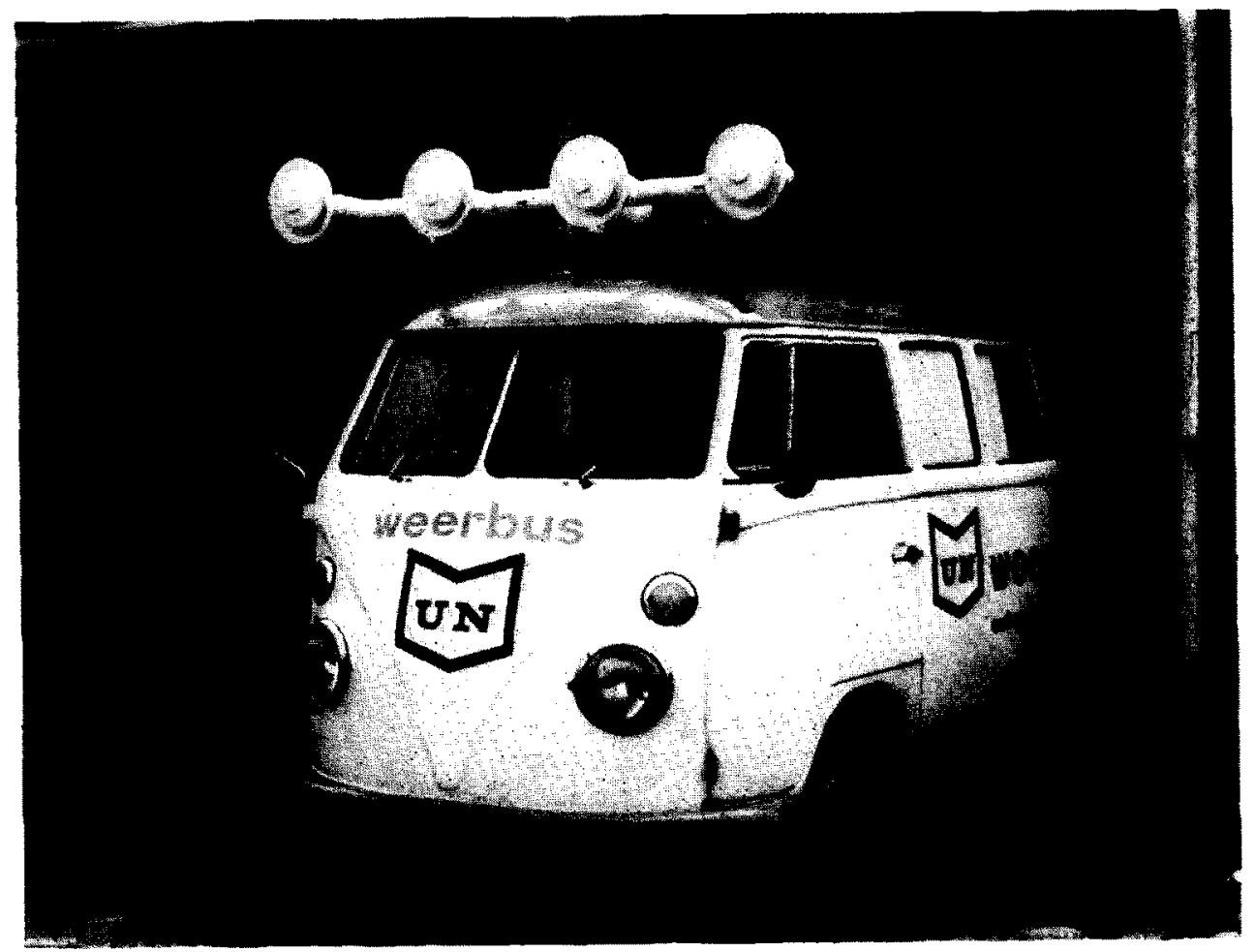

FIG. 1. Four thermo-couples are mounted separately inside radiation screens, each provided with a rain shield and a funnel shaped device to maintain constant ventilation. 


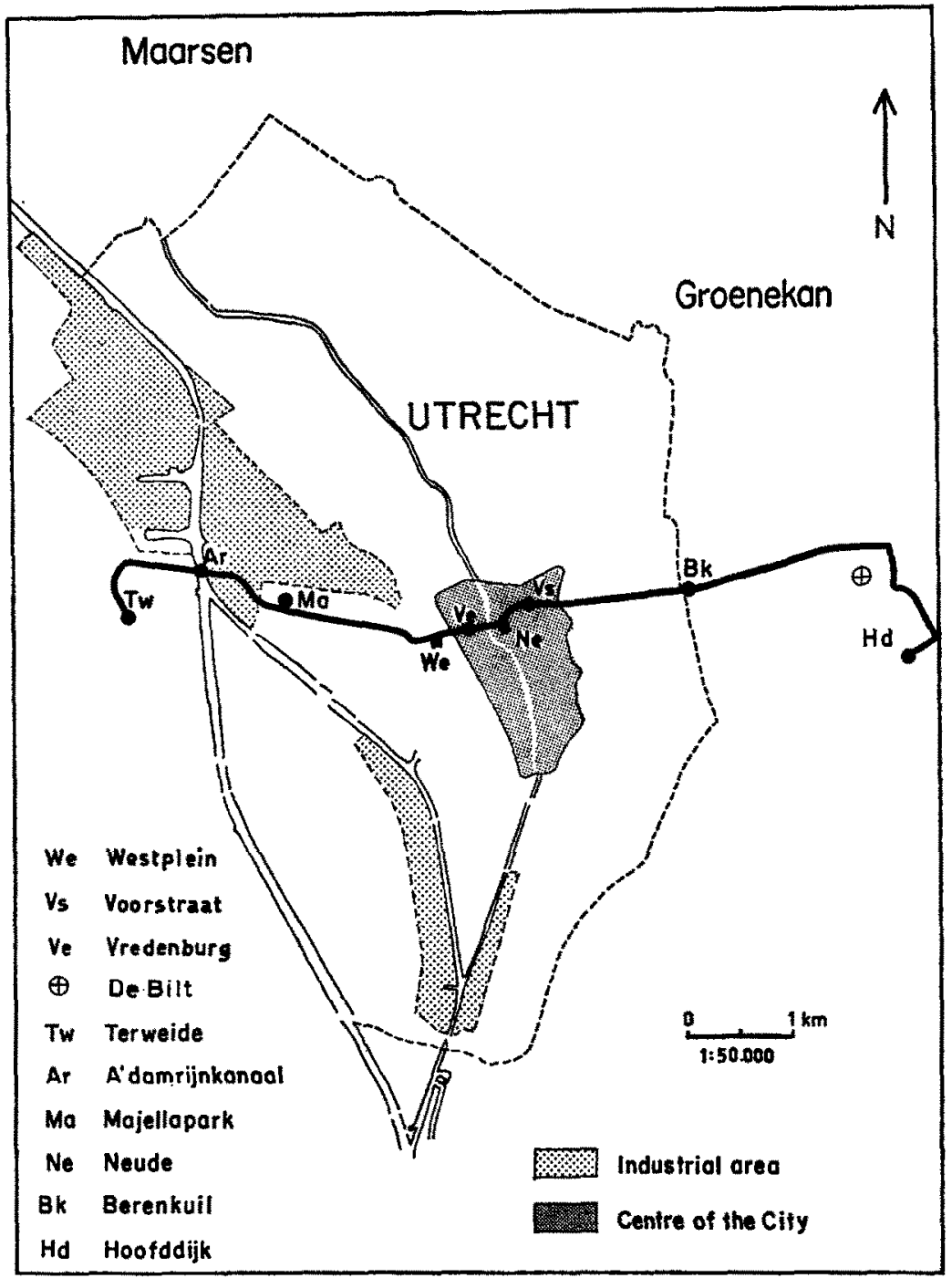

Fig. 2. The E-W traverse in the City of Utrecht and its neighbourhood. Pay particular attention to the position of the square marked $\mathrm{Ne}$ in the centre of the city.

From each month one traverse has been chosen, which very clearly demonstrates the influence of open places.

For comparison the mean monthly temperatures and the temperatures corresponding to the three traverses referring to $7.30 \mathrm{~h}$ M.E.T. and the meteorological station De Bilt (see FiG. 2) have been placed in this figure also.

TABLE 1 gives information on the meteorological conditions on the selected days.

These figures, in the international synoptic code refer to the meteorological station De Bilt.

As we can see from TABLE 1 the three days were characterized by low wind speeds ( $\leqslant 3 \mathrm{kts}$ ), a visibility of $3500 \mathrm{~m}$ or less and fog (ww 11, 28 and 42) or haze (ww 10) mainly outside of the city. 


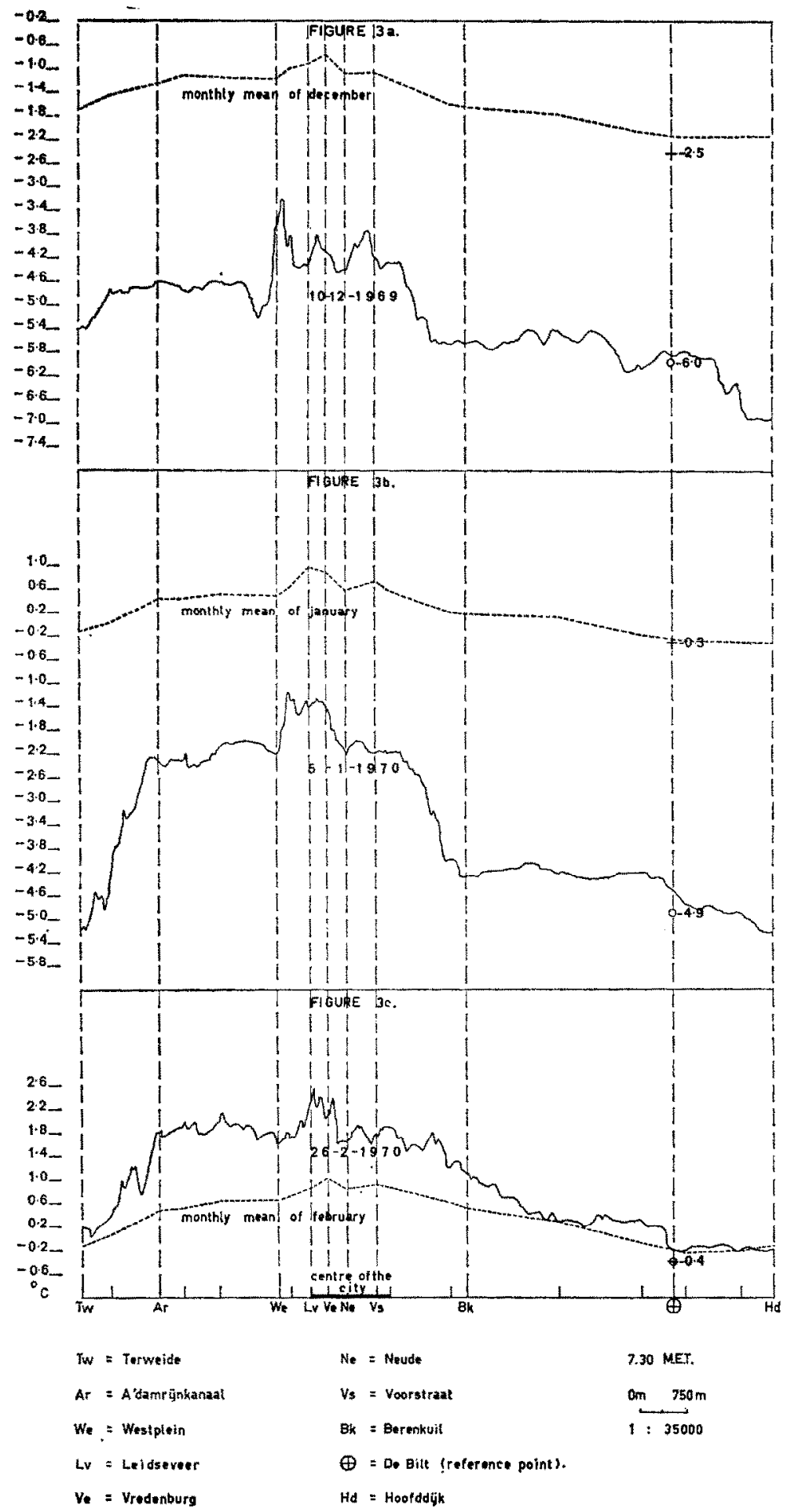

Fro. 3. Mean monthly temperature values along the $\mathrm{E}-\mathrm{W}$ traverse in the city of Utrecht and three actual temperature profiles for each of the months December 1969, January and February 1970. 
TABLE 1

\begin{tabular}{llllllll}
\hline Traverse & M.E.T. & N & dd & ff & wv & ww & W \\
\hline Wednesday & 07.00 & 0 & 14 & 2 & 35 & 11 & 4 \\
$\quad 10-12-1969$ & 10.00 & 0 & 16 & 2 & 20 & 10 & 0 \\
& & & & & & & \\
Monday & 07.00 & 5 & 34 & 1 & 17 & 10 & 2 \\
$\quad 5-1-1970$ & 10.00 & 6 & 34 & 2 & 15 & 28 & 2 \\
Thursday & 07.00 & 7 & 32 & 2 & 09 & 42 & 4 \\
$\quad 26-2-1970$ & 10.00 & 7 & 01 & 3 & 30 & 05 & 8 \\
\hline
\end{tabular}

$\mathbf{N}=$ cloud amount (in eighths of sky cover).

$\mathrm{dd}=$ wind-direction (in tenths of degrees).

$\mathrm{ff}=$ wind-speed (in knots).

$\mathrm{vv}=$ visibility (in hundreds of meters).

$\mathrm{ww}=$ present weather (according to the synoptic code).

$\mathrm{W}=$ past weather (according to the synoptic code).

The influence on the temperature distribution of the cloudless sky, which is one of the conditions favourable for the development of the heat island, on 10-12-1969 was obscured by the presence of radiation fog in and outside the city.

On the other hand, the presence of fog or haze outside the city stimulated temperature differences between the city and its environment in several other temperature traverses.

A maximum temperature difference of almost $6.0^{\circ} \mathrm{C}$ between the open country and the city centre was found under such circumstances on 9-12-1969.

The mean monthly temperatures in January and February of Terweide (Tw) and Hoofddijk (Hd) are below $0.0^{\circ} \mathrm{C}$, while the centre of the city shows values above zero.

In examining temperature profiles during this winter, we found situations in which the air temperature in the city was above freezing point, while outside of the city temperatures well below freezing point were measured. These types of horizontal temperature patterns induced by the city can have an important influence on road conditions in winter time.

The heating influence of the industrial area situated north of the Amsterdamrijnkanaal (Ar) can be recognized in the monthly mean values, and is very remarkable in the actual temperature profiles on 5-1-1970 and 26-2-1970.

Secondary minima in the monthly mean temperature profiles of the three months can be seen as the car passes through the square Neude (Ne) and an open traffic circus, Westplein (We). Only the influence of the square Neude (Ne) will be discussed in more detail now.

The mean monthly temperature values from Neude $(\mathrm{Ne})$ and the adjacent values of the points Voorstraat (Vs) and Vredenburg (Ve), the mean monthly temperature differences and the significance levels $(P)$ for the observed differences based on the application of the Sign-test to the temperature data are shown in TABLE 2.

We may conclude, that during this period the mean air-temperature of the square Neude was lower than in the adjacent streets and that the observed temperature differences were significant for the morning tours in the winter of 1969/1970. 
TABLE 2

\begin{tabular}{lccccccc}
\hline & $\bar{T}_{\mathrm{vs}}$ & $\bar{T}_{\mathrm{Ne}}$ & $\bar{T}_{\mathrm{Ve}}$ & ${\overline{\Delta T_{\mathrm{Ne}} \mathrm{vs}}}$ & $P_{\mathrm{Ne}}<\mathrm{vs}$ & ${\overline{\Delta T_{\mathrm{Ne}} \mathrm{ve}}}_{\mathrm{N}}$ & $P_{\mathrm{Ne}}<\mathrm{ve}$ \\
\hline $\begin{array}{l}\text { December } \\
\quad 1969\end{array}$ & -1.06 & -1.08 & -0.75 & -0.02 & 0.05 & -0.33 & $<0.01$ \\
$\begin{array}{l}\text { January } \\
\quad 1970\end{array}$ & +0.74 & +0.61 & +0.91 & -0.13 & 0.01 & -0.30 & $<0.01$ \\
$\begin{array}{l}\text { February } \\
\quad 1970\end{array}$ & +0.90 & +0.82 & +1.01 & -0.08 & 0.01 & -0.19 & $<0.01$ \\
\hline
\end{tabular}

We can also arrange the 90 traverses as follows:

TABLE 3

\begin{tabular}{|c|c|c|c|}
\hline \multirow{2}{*}{$\begin{array}{c}\text { Total number } \\
\text { of traverses }\end{array}$} & \multicolumn{3}{|c|}{ Number of traverses in which: } \\
\hline & $T_{50}<T_{\mathrm{Vs}}$ & $T_{\mathrm{Ne}}=T_{\mathrm{Vs}}$ & $\underset{19}{T_{\mathrm{Ne}}>T_{\mathrm{Vs}}}$ \\
\hline 90 & $\underset{71}{T_{\mathrm{Ne}}<T_{\mathrm{Ve}}}$ & $T_{\mathrm{Ne}}=T_{15} T_{\mathrm{ve}}$ & $T_{\mathrm{Ne}}>4 T_{\mathrm{ve}}$ \\
\hline
\end{tabular}

The three actual temperature-recordings present a rather irregular shape, caused by (1) open sites in the built up area, (2) fog patches or (3) high traffic densities.

On 26-2-1970 the temperature recording is much more complicated by the influence of showers (TABLE $1, \mathrm{~W}=8$ ).

When passing the square Neude the temperature falls a few tenths of a degree, probably as a result of entering another microclimate characterized by a greater horizontal and vertical mixing compared with the local turbulence of the adjacent streets.

But there are other temperature dips to be found which so far we have been unable to explain. The authors are now investigating these temperature changes in more detail.

\section{CONCLUSION}

The heat-island effect in the winter $1969 / 1970$ for the city of Utrecht, a relatively small town situated at a distance of $50 \mathrm{~km}$ from the North Sea, is surprisingly evident.

The method discussed in this paper may be considered as an improvement of the air-temperature measurements used in urban climatological research up to now (LUDWIG, 1967; SCHULzE, 1969) and can be used for detecting the influence of squares, cross-roads, canals and parks on horizontal distributions of the air-temperature during all weather conditions.

During peak traffic hours however, the influence of cross-roads is masked by the temperature-rises caused by the higher traffic density round these points.

Acknowledgements-The authors are indebted to the newspaper "Utrechts Nieuwsblad" for their offer of the VW-bus to be used in urban climatological studies in the city of Utrecht and the Royal Netherlands Meteorological Institute for supplying hourly temperature values of the meteorological station De Bilt. 


\section{REFERENCES}

LuDwio F. L. (1967) Urban climatological studies, Interim Report No. 1, Contract OCD-PS-64-201 under Work Unit 1235A, Stanford Research Institute.

SchUlze P. (1969). Die horizontale Temperaturverteilung in Grossstädten, insbesondere die WestBerlins in Winterlichen Strahlungsnächten. Inst. f. Met. u. Geoph. der Freien Universität Berlin, Met. Abh. Band XCI Heft 2. 